\title{
24. GEOCHEMISTRY OF TETRAPYRROLE PIGMENTS IN SEDIMENTS OF THE NORTH PHILIPPINE SEA, DEEP SEA DRILLING PROJECT LEG 58
}

\author{
Earl W. Baker and J. William Louda, Organic Geochemistry Group, \\ Florida Atlantic University, Boca Raton, Florida
}

\section{INTRODUCTION}

Nineteen core samples from the Shikoku Basin and the Daito Ridge and Basin province of the northwest Philippine Sea, obtained from DSDP Leg 58, were examined for products of chlorophyll diagenesis; we aimed at gaining a better understanding of the very early diagenetic history of sedimentary chlorophyll.

We choose samples which, a priori, would allow isolation of tetrapyrrole pigments characteristic of (destructive) diagenesis modes. Studies of Japan Trench sediments (Louda et al., in press; Baker and Louda, in press) showed well the interplay of two main diagenesis schemes: anoxic preservation and oxic destruction. The results reported herein are a product of a preliminary investigation on sediments of scant organic matter content, which yielded limited tetrapyrrole pigment.

\section{EXPERIMENTAL PROCEDURE}

A 250-gram aliquot (wet weight) of each core sample was exhaustively extracted with acetone:methanol (9:1 vol.) using a ball mill. Subsequent separation and purification of pigments were in accordance with the methods of Baker and Louda (in press) and Louda et al. (in press). Electronic spectral data are presented as obtained in tetrahydrofuran, because of contamination of isolates by vast amounts of unidentified "hydrocarbon impurities" which hampered dissolution of isolates in ethyl ether.

Recently we computed a pigment yield index, PYI (Louda et al., in press). PYI has been refined to include a correction to dry weight of sediment (Baker and Louda, in press). The corrected PYI data can now be used quantitatively for assessing the relative destruction or preservation of tetrapyrrole pigments as a constituent of organic-carbon assemblages in various sedimentary environments. The correction for water content in sediment samples (i.e., PYI, dry) negates some comparison problems (e.g., varying degrees of compaction), but not all.

\section{RESULTS}

Electronic absorption spectra of tetrapyrrole-pigment isolates and pigment yield data are presented in Table 1. Seven of 19 examined core samples yielded detectable amounts of pigments.

Because of low organic-carbon content (0.05-0.41\%, dry wt.), extractions were performed on much larger $(250-\mathrm{g})$ aliquots of core samples than usual $(100 \mathrm{~g})$. Even with this 2.5 -fold increase in sample size, the total pig- ment isolates were extremely small $(0-100 \mu \mathrm{g})$. During our recent investigations we have begun tracing tetrapyrrole pigment survival and destruction quantitatively by employing the PYI. Plotting PYI, dry versus subbottom depth (Figure 1), one is able to observe alterations in the chlorophyll derivative portion of the total organic carbon. A very rapid demise of tetrapyrrole pigments was found for sediments from each of the five Leg 58 sites. Included in Figure 1 is a comparison with previously reported data for DSDP Site 440 Leg 57; (Baker and Louda, in press).

Absorption spectra are seen to possess long-wavelength (low-energy) absorption bands in the region of 680 to $690 \mathrm{~nm}$. This absorption is characteristic of an oxidized series of chlorophyll derivatives, which includes the purpurins and chlorins- $\mathrm{e}_{6} /-\mathrm{p}_{6}$. (For structures, see Seely, 1966). In the shallowest sediment samples examined (5-12 m sub-bottom), tetrapyrrole pigment isolates exhibited absorption spectra characteristic of mixtures of phorbins (e.g., pheophorbidelike, with intact isocyclic ring; Figure 2) and the previously mentioned oxidized derivatives.

\section{DISCUSSION}

The paucity of chlorophyll derivatives in sediments obtained from Leg 58 operations reflects both the low proportion of organic matter and the predominance of an oxidative mode of diagenesis.

Recently we have begun investigating abiotic modes of oxidation during the early diagenesis of chlorophyll (Baker and Louda, in press). A prevalence of chlorins of the purpurin and chlorin $-\mathrm{e}_{6} /-\mathrm{p}_{6}$ series is now being viewed as an indication that oxidative-destruction mechanisms were the predominant mode of diagenesis. The existence of tetrapyrrole pigments exhibiting long-wavelength red absorption bands $(680-690 \mathrm{~nm})$ in sediments from the northwest Philippine Sea lends credence to this postulate. This is further indicated by the extremely rapid loss of tetrapyrrole pigment from the fossil record in the present case (Figure 1), and previously examined sedimentary sequences which yielded purpurin and chlorin- $\mathrm{e}_{6} / \mathrm{p}_{6}$-like compounds (cf., Site 436 in Louda et al., in press; Site 438 in Baker and Louda, in press).

Preservation of chlorophyll derivatives has been found in sedimentary environments with a rapid change to negative oxidation potentials (Kemp and Lewis, 1968; Koyama et al., 1968; Orr et al., 1958), in environments with methanogenic conditions (Rashid and Vilks, 1977), and in regions of low heat flow and early compaction (Site 440 in Baker and Louda, in press). 
TABLE 1

Description and Tetrapyrrole-Pigment Yield of Sediment Samples from DSDP Leg 58 Sites

\begin{tabular}{|c|c|c|c|c|c|c|c|}
\hline $\begin{array}{l}\text { Sampled } \\
\text { Section }\end{array}$ & $\begin{array}{l}\text { Sub- } \\
\text { Bottoma } \\
\text { Depth } \\
\text { (m) }\end{array}$ & Agea & $\begin{array}{l}\text { Lithologic } \\
\text { Descriptiona }\end{array}$ & $\begin{array}{c}\text { Organic Carbonb } \\
(\%, \text { dry wt.) }\end{array}$ & $\begin{array}{l}\text { Tetrapyrrole Yieldc } \\
\text { ( } \mu \mathrm{g} / \mathrm{g} \text { sediment, } \\
\text { dry wt.) }\end{array}$ & $\begin{array}{c}\text { PYIC } \\
\text { (dry wt.) }\end{array}$ & $\begin{array}{c}\text { Absorption Spectra } \\
(\mathrm{nm})\end{array}$ \\
\hline $442 \mathrm{~A}-2-3$ & 12 & U. Pleistocene-Holocene & Dark green to gray silty clay & 0.40 & 0.331 & 0.84 & $410,610,668(690)$ \\
\hline $442 A-7-3$ & 55 & Pleistocene & Green to gray clay & 0.30 & 0.093 & 0.31 & $405,609,667(690)$ \\
\hline $442 \mathrm{~A}-14-2$ & 125 & Pleistocene & Gray clay & 0.19 & 0.006 & 0.04 & -666 \\
\hline $442 \mathrm{~A}-28-2$ & 215 & M. Miocene & Yellow-brown clay & 0.10 & n.d. & - & - \\
\hline $443-2-4$ & 15 & U. Pleistocene & Green to gray silty clay, mildly calcareous & 0.41 & 0.428 & 1.05 & $410,610,667(690)$ \\
\hline $443-9-4$ & 75 & Pleistocene & Green to gray carbonate mud & 0.10 & 0.053 & 0.53 & -665 \\
\hline $443-23-3$ & 205 & U. Miocene & Yellow-brown ashy and nannofossil mud & 0.10 & n.d. & - & - \\
\hline $443-34-2$ & 325 & U. Miocene & Gray to tan nannofossil-rich mudstone & 0.07 & n.d. & - & - \\
\hline $443-43-1$ & 400 & L.-M. Miocene & Light-gray mudstone & 0.10 & n.d. & - & - \\
\hline $444-2-4=$ & 5 & U. Pleistocene & Gray to green mud & 0.18 & 0.085 & 0.48 & $410,610,668(690)$ \\
\hline $444-7-5 ?$ & 55 & U. Pleistocene & Light-gray vitric ashy mud & 0.06 & n.d. & - & - \\
\hline $445-1-4$ & 5.5 & U. Pleistocene-Holocene & Light-gray nannofossil-foraminifer ooze & 0.15 & $0.002^{\mathrm{c}}$ & - & -652 \\
\hline $445-6-5$ & 50 & U. Pliocene & Tan nannofossil ooze & 0.09 & n.d. & - & - \\
\hline $445-11-2$ & 100 & U. Pliocene & Cream to gray nannofossil ooze & 0.07 & n.d. & - & - \\
\hline $445-32-2$ & 299 & L.-M. Miocene & Dark-brown clayey mudstone & 0.08 & n.d. & - & - \\
\hline $445-83-3$ & 780 & M. Eocene & Dark-gray calcareous sandy mudstone & 0.09 & n.d. & - & - \\
\hline $446-3-5$ & 20 & Miocene & Dark-tan muddy clay & 0.06 & n.d. & - & - \\
\hline $446-9-4$ & 75 & U.-L. Miocene & Dark-brown pelagic clay & 0.05 & n.d. & - & - \\
\hline $446-14-4$ & 120 & M. Oligocene & Red-brown zeolitic clay & 0.06 & n.d. & - & - \\
\hline
\end{tabular}

asite reports, this volume.

bOrganic Geochemistry Sample Inventory, DSDP/IPOD Leg 58.

"Calculated using $\alpha=63.7 \mathrm{~g}-\mathrm{cm}^{-1}$ for "chlorin-like" electronic spectra in tetrahydrofuran solvent; n.d. = not detectable; Pigment Yield Index (PYI; Louda et al., in press) equals tetrapyrrole pigment in $\mu \mathrm{g} / \mathrm{g}$ (dry wt.) divided by organic carbon in \%dry weight; sediment corrected to dry weight utilizing water-content data from Site reports, this volume.

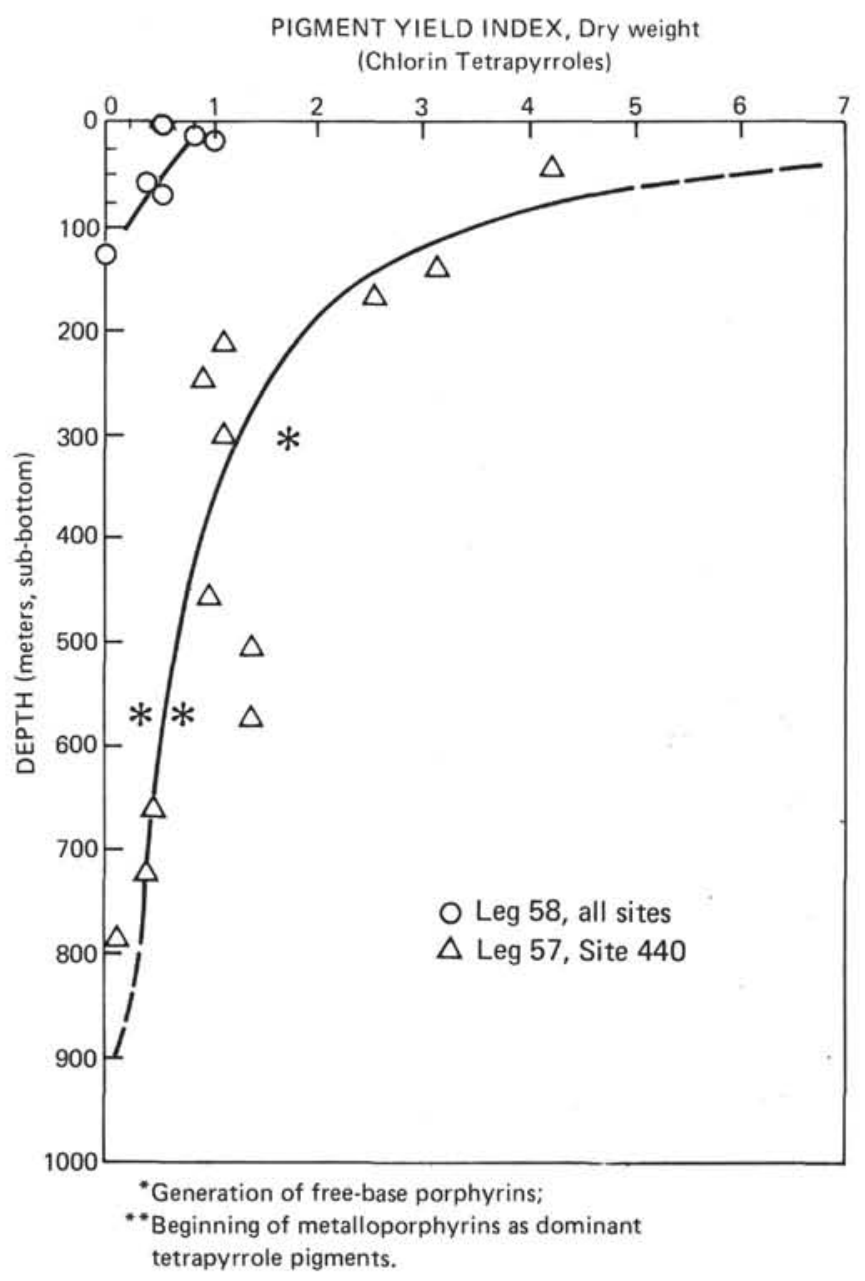

Figure 1. Pigment Yield Index (PYI, dry) versus subbottom depth.

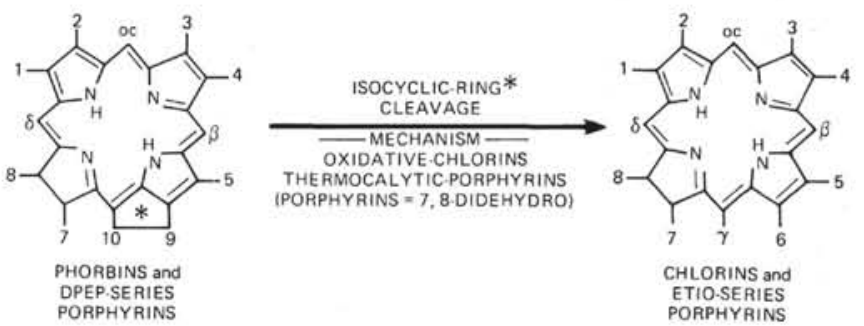

Figure 2. Structural relationship between phorbinschlorins and DPEP-etio porphyrins due to isocyclic ring cleavage.

The major structural difference between phorbins and chlorins (including purpurins) is the respective presence or absence of the isocyclic ring. The isocyclic ring is the non-nitrogenous pentacycle, including carbons 9 and 10, in Figure 2. The retention of the isocyclic ring in the early diagenesis of chlorophyll appears to stabilize the tetrapyrrole macrocycle. This now appears to assure sufficient pigment survival to a depth of burial which imparts the required stresses (heat, compaction, anaerobic conditions) for aromatization and, hence, generation of the geochemically more stable free-base and subsequent metalloporphyrins. In the present study the early oxidative cleavage of the isocyclic ring, generating purpurin and chlorin- $\mathrm{e}_{6} /-\mathrm{p}_{6}$-like compounds, is paralleled by extremely rapid down-hole pigment loss. This was previously reported for Site 438 sediments from Leg 57 (Baker and Louda, in press).

A contrary argument can be raised that it is not the generation of these "altered chlorins" (i.e., purpurin and chlorin- $\mathrm{e}_{6} /-\mathrm{p}_{6}$ compounds) which is responsible for the continued and complete loss of tetrapyrrole pigments from the geologic record, but rather the overall 
oxidation and hence loss of all organic matter. However, even in strata which have become stabilized and shift to anoxic conditions, purpurin and chlorin- $\mathrm{e}_{6}$ / $-\mathrm{p}_{6}$-like compounds are still found, and tetrapyrrole pigment demise is rapid and usually complete (cf. Site 438 results in Louda et al., in press). These "altered chlorins" have been reported from Pleistocene samples of DSDP Leg 22 and from Neogene strata of the Walvis Ridge (Baker et al., 1978), and were entirely absent from the anoxic Black Sea sediments (Baker et al., 1978). The parallels among oxic sedimentary conditions, "altered chlorins," and extremely rapid loss of tetrapyrrole pigment relative to the remainder of organic carbon point dramatically to the destabilizing effect which early oxidative cleavage of the isocyclic ring has on tetrapyrrole-pigment integrity.

Survival of chlorophyll derivatives results from decreased exposure to aerobic conditions, rapid stabilization of sediment profiles (lack of reworking), and an initially high quantity of non-reworked chlorophyllous organic matter. Stable reducing environments, showing much decreased tetrapyrrole loss rates (Baker et al., 1978; Baker and Louda, in press) apparently allow chlorophyll diagenesis to reach a quasi-steady state and thereby generate the significantly more-stable porphyrins and metalloporphyrins.

Examination of Figure 1 allows some clarification of the problem of tetrapyrrole survival to a stage where genesis of stable biologic marker occurs. An extremely rapid loss of chlorin tetrapyrroles was noted throughout approximately the first 200 to 300 meters of sediment burial for samples from Site 440 (DSDP Leg 57), after which a relative decrease in pigment loss occurs, during which free-bases and metalloporphyrins, in that order, could first be detected. As free-bases and, especially, metalloporphyrins become dominant, the level of chlorin tetrapyrrole decreases until below the limit of detection. This trend in relatively stable sediments has been reported during our studies on Black Sea sediments (Baker et al., 1978).

The rapid and complete loss of chlorophyll derivatives observed throughout each sample suite from Leg 58 operations vividly points out that the conditions which assure preservation of these geochemical fossils are rather stringent. At present, the mechanism of tetrapyrrole destruction is unknown. The repeated occurrence of purpurin and chlorin- $\mathrm{e}_{6} /-\mathrm{p}_{6}$-like compounds, prevalent in Leg 58 sediment samples, is consistently paralleled by an extremely rapid loss of chlorophyll derivatives from the fossil record. Early oxidative cleav- age of the isocyclic ring is now viewed as destabilizing the macrocyclic tetrapyrrole structure to such a degree that further oxidation and complete destruction of these pigments, whether biotic or abiotic, is relatively facile.

In summary, tetrapyrrole pigments isolated from sediments obtained from DSDP Leg 58 were found to be indicative of an early oxic depositional mode. Since these sediments were generated from low-productivity pelagic regions, are reworked, are high in carbonate, and contain abundant fecal organic matter, sedimentary chlorophyll was exposed to increased oxidative forces and, hence, was removed from the fossil record.

\section{ACKNOWLEDGMENTS}

These studies have been supported by the National Science Foundation (Grant No. OCE-74-12438-02). The authors thank Ms. Debra Murphy for assistance in sample preparation and the Deep Sea Drilling Project and associated agencies for obtaining these unique sample suites.

\section{REFERENCES}

Baker, E. W., Palmer, S. E., and Huang, W. Y., 1978. Early and intermediate chlorophyll diagenesis of Black Sea Sediments: Sites 379, 380 and 381. In Ross, D. A., Neprochnov, Y. P., et al., Init. Repts. DSDP, 42, Part 2: Washington (U.S. Govt. Printing Office), pp. 707-715).

Baker, E. W. and Louda, J. W., in press. Products of chlorophyll diagenesis in Japan Trench sediments: Part II-DSDP/IPOD Sites 438-439 and 440. In von Huene, R., Nasu, N., et al., Init. Repts. DSDP, 56, 57, Pt. 2: Washington (U. S. Govt. Printing Office).

Kemp, A. L. W. and Lewis, C. F. M., 1968. A preliminary investigation of chlorophyll degradation products in the sediments of lakes Erie and Ontario. Proc. 11th Conf. Great Lakes Res., pp. 206-229.

Koyama, T., Shimomura, O., and Yangi, K., 1968. Vertical distribution of pigments in a lake sediment as determined by paper chromatography. Geochem. J., 2, 87-103.

Louda, J. W., Palmer, S. E., and Baker, E. W., in press. Products of chlorophyll diagenesis in Japan Trench sediments: Part I-DSDP/IPOD Sites 434, 435, 436. In Langseth, M., Okada, H., et al., Init. Repts. DSDP, 56, 57, Pt. 1: Washington (U. S. Govt. Printing Office).

Orr, W. L., Emery, K. O., and Grady, J. R., 1958. Preservation of chlorophyll derivatives in sediments off Southern California. Bull. Amer. Petrol. Geol., 42, 925-962.

Rashid, M. A. and Vilks, G., 1977. Environmental controls of methane production in holocene basins in eastern Canada. Org. Geochem. 1, 53-59.

Seely, G. R., 1966. The structure and chemistry of functional groups. In Vernon, L. P. and Seely, G. R., The Chlorophylls, New York (Academic Press), pp. 67-110. 